\title{
The MD express lane
}

I t won't be pumping out Doogie Howsers by the dozen, but an Ontario university may soon be producing doctors a little less long in the tooth than the average medical graduate. Starting in 2012, a few gifted high school students may find themselves on a fast track to earning medical degrees in six years, rather than the usual eight, at Queen's University in Kingston.

The concept may be novel for Canada, but is fairly common in the United Kingdom, Australia and the United States, where it is called a BS/MD (bachelor science/doctor of medicine) program. One theory for offering such a program is the hope that a reserved spot in medical school and a quicker path to academic and career goals will attract the brightest students.

Approval appears likely for the proposed Accelerated Pathway to Medical School program at Queen's. Only 10 students would be accepted into the program each year, and they will have to be more than just intelligent, according to Michael Kawaja, associate dean of life sciences and biochemistry at the university. They must be creative, altruistic, humanistic and curious. They must exhibit leadership, communication and critical-thinking skills. They must possess a history of extracurricular activities and community involvement. "That's a long list, but it's absolutely critical to find that total package," he says.

But will finding 10 total packages be a problem? Apparently not.

"We think these $10 \mathrm{kids}$ are out there," says Dr. Richard Reznick, dean of Queen's Faculty of Health Sciences. "We know they're out there — in fact, there's probably hundreds of high school students who fit that description."

Another form of accelerated medical education involves compressing medical school into three years from four years by requiring students to attend class year round, thus reducing the overall time period required to obtain

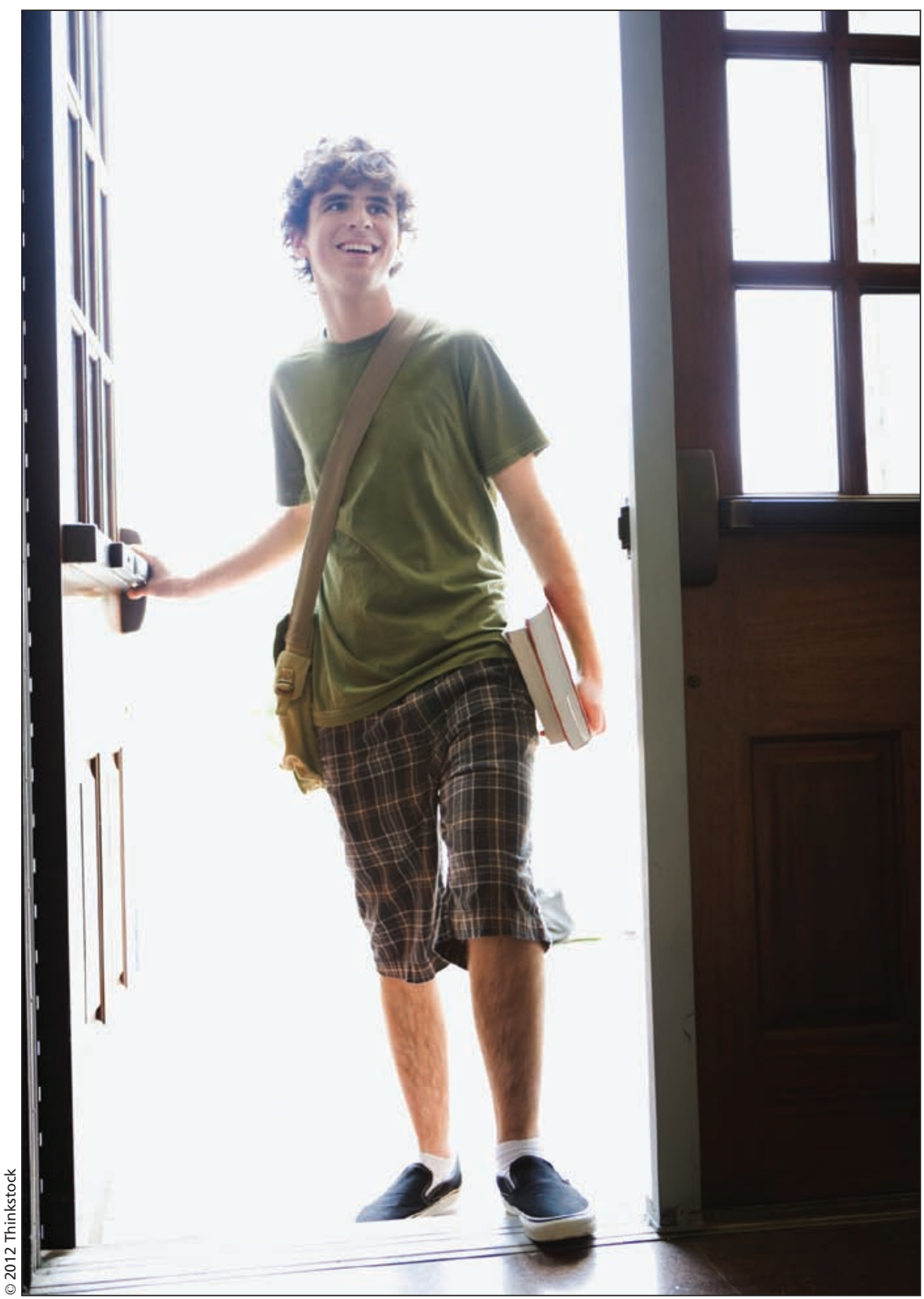

Knowing there is a spot waiting for them in medical school the first day they enter university brings peace of mind for some students.

an MD to seven from eight years. That is the model adopted by the University of Calgary in Alberta, where the majority of medical school entrants have completed bachelor degrees.

Although it's three years of med school rather than four, "it's not threequarters of the experience," says Dr.
Bruce Wright, associate dean of undergraduate medical education at the University of Calgary. "We go all year round."

By not taking summers off, the medical school is able to meet the accreditation standard of 130 total weeks of instruction, set by the Liaison Commit- 
tee on Medical Education for Canadian and American medical schools. In fact, the school actually exceeds that number by two, offering 132 weeks of medical education. The program attracts serious students who don't mind the added intensity of a compressed schedule.

"One of the reasons we do it is because we believe we should start treating future doctors how they are going to be in terms of time commitment when they are in practice," says Wright. "We treat them like professionals from the get-go."

The advantage to the health care system is that doctors, always in demand, enter the workforce sooner. The advantage for students is a reduction in time requirements and, just as importantly, in costs.

"This does allow those people who want an accelerated program to get on with it and save a year, and save some costs - certainly on living costs, like renting apartments," says Jocelyn Lockyer, senior associate dean of education for the faculty of medicine at the University of Calgary.

As for performance, Calgary students are competitive on showings in the medical council exams and the annual residency match, says Wright. In addition, faculty members at the medical school have analyzed how their students fare in the profession compared to those in traditional four-year medical programs, such as the one at the University of Alberta. A look at long-term outcomes, using data from the College of Physicians and Surgeons of Alberta Physician Achievement Review program, suggested "at least equivalent performance for graduates of three- and four-year medical schools who practice in Alberta" (Acad Med 2009;84:1342-7).

A similar analysis, this one looking only at surgeons, indicated that "if the duration of medical school programs could be adjusted, graduates could train in surgery and be ready for practice
1 year earlier without any detectable differences in competency on our assessment tool" (Can J Surg 2012; 55:S163-70).

Still, there are disadvantages to threeyear medical school programs, acknowledges Lockyer, the primary author on both papers. The compressed schedule puts the medical school out of sync with the rest of the university, which can lead to logistical problems. And even though students take less time off, they still can't squeeze in as many weeks of education as most four-year programs.

"The difference is they haven't had as many clinical experiences," says Lockyer. "The three or four extra months that a four-year-program has would provide more clinical time and a bit more time to mature and think about their career choices."

Indeed, students in four-year programs do appear more prepared to make decisions about what type of careers they want to pursue in medicine, according to a comparison of the "career maturity" of medical students in accelerated and traditional programs (Career Dev Q 2007;56:171-6). The paper recommends that accelerated programs provide additional career guidance for their students.

"When you think about career decisions in general, people go through stages of development. It starts during early periods of awareness and exploration. As you get older, you learn more about the world of work and you start to understand more," says George Richard, one of the paper's authors and the director of careers in medicine at the Association of American Medical Colleges. "The students in traditional programs have had more time and opportunities to explore and understand what the field of medicine is about. Students in accelerated programs don't have as much time and as many opportunities to do the kinds of activities needed during those stages of development."
For some high school students, though, having a spot waiting for them in medical school, rather than competing for one after completing a bachelor's degree, brings peace of mind. "The anxiety is removed because they have a reserved seat, and typically they get to where they want to go faster," says Stephen Manuel, assistant dean of admissions at the University of Cincinnati College of Medicine in Ohio.

The University of Cincinnati follows the traditional " 4 plus 4" model, but Manuel has been part of accelerated programs in the past, and says another advantage of reserving spots for high school students is the opportunity to provide extra resources for those who might struggle adjusting to university life. For example, a medical school attempting to attract more students from rural areas, in hopes they will return to those areas to practise medicine, could provide services to help those students succeed in their first year away from home.

But enrolment in an accelerated program may prove stressful for students who, after a couple of years of study, are no longer convinced they want to be physicians. After all, family and friends may already have visions of stethoscopes and white coats, while program administrators have certain expectations, having spent much time and effort to select the candidate from among a large pool and singled them out for an accelerated medical education.

"Students are having to make that selection of medicine as a career that much earlier, and the issue is that they sometimes feel they are on a path that they have to continue on," says Manuel. "To step off that path can be hard for students to deal with." - Roger Collier, $C M A J$, with files from Michael Monette, $C M A J$

CMAJ 2012. DOI:10.1503/cmaj.109-4301 